\title{
Kinerja Green Supply Chain Management Dilihat Dari Aspek Reverse Logistic dan Green Procurement pada UKM Kuliner di Kota Palembang
}

\author{
Heriyanto \\ Universitas Bina Darma \\ Email: heriyanto@binadarma.ac.id \\ Andrian Noviardy \\ Universitas Bina Darma \\ Email: andrian.noviardy@binadarma.ac.id
}

\begin{abstract}
The study aims to determine the performance of Green Supply Chain Managament viewed from the aspect of Reverse Logistics and Green Procuretment In Culinary Ukm Dikota Palembang.pada Culinary SME Palembang City.As a city that has a wealth of diverse culinary, culinary SMEs are expected to participate in supporting environmentally sound development. This is because the concept of Green Supply Chain Management (GSCM) is a concept that aims to minimize the negative impact of an organization and its supply chain on the environment related to climate change, pollution and non-renewable resources. In order to support GSCM, it is necessary to evaluate the extent to which this concept is carried out by Culinary SMEs in Palembang City. This evaluation is expected to identify the constraints and barriers facing SMEs in doing GSCM. By conducting a survey of 36 culinary SMEs, it was found that culinary SMEs in Palembang City have not implemented GSCM practices. This can be seen from the low mean value. Therefore, there needs to be support from related parties in this case the government to conduct socialization and dive and assistance in GSCM.
\end{abstract}

Keywords: Cullinary SMEs, GSCM

\begin{abstract}
Abstrak
Penelitian bertujuan untuk mengetahui kinerja Green Supply Chain Managament dilihat dari aspek Reverse Logistic dan Green Procuretment Pada Ukm Kuliner Dikota Palembang.pada Kuliner UKM Kota Palembang. Sebagai kota yang memiliki kekayaan kuliner yang beragam, UKM kuliner diharapkan mampu untuk ikut serta dalam mendukung pembangunan yang berwawasan lingkungan. Hal ini dikarenakan konsep Green Supply Chain Manajemen (GSCM) merupakan suatu konsep yang bertujuan untuk meminimalkan dampak negatif dari suatu organisasi dan rantai pasoknya terhadap lingkungan yang berkaitan dengan perubahan iklim, polusi dan sumber-sumber daya yang tidak diperbaharui. Dalam rangka mendukung GSCM, perlu untuk melakukan evaluasi sejauh mana konsep ini dilakukan oleh UKM Kuliner yang ada di Kota Palembang. Dengan dilakukannya evaluasi ini diharapkan dapat diidentifikasi kendala dan hambatan yang dihadapi UKM dalam melakukan GSCM. Dengan melakukan survey terhadap 36 UKM kuliner, ditemukan bahwa UKM kuliner di Kota Palembang belum melaksanakan praktek-praktek GSCM. Hal ini terlihat dari nilai mean yang masih rendah. Untuk itu perlu adanya dukungan dari pihak terkait dalam hal ini pemerintah untuk melakukan sosialisasi dan penyuluhan dan pendampingan dalam melaksanakan GSCM.
\end{abstract}

Kata kunci: UKM kuliner, GSCM

\section{Pendahuluan}

Konsep Green Supply Chain Manajemen (GSCM) mengacu pada usaha-usaha untuk meminimalkan dampak negatif dari suatu organisasi dan rantai pasoknya terhadap lingkungan yang berkaitan dengan perubahan iklim, polusi dan sumber-sumber daya yang tidak diperbaharui. GSCM mengintegrasikan supply chain management dengan tujuan mengurangi dampak lingkungan yang diakibatkan siklus hidup produk (product life cycle) dengan melakukan harmonisasi dengan supply chain partner untuk melakukan 
tindakan-tindakan yang menunjang proses bisnis yang berwawasan lingkungan. Dalam mewujudkan hal ini, aktivitas-aktivitas yang terkait didalamnya adalah kerjasama suppliers dan customer, analisa proses dan operasi secara internal, pertimbangan faktorfaktor lingkungan dalam proses pengembangan produk dan pengawasan yang berkelanjutan antar siklus hidup produk (Corbett dan Klassen, 2006).

Strategi GSCM merupakan konsep yang mengacu pada usaha-usaha untuk meminimalkan dampak negatif dari suatu organisasi dan rantai pasoknya terhadap lingkungan yang berkaitan dengan perubahan iklim, polusi dan sumber-sumber daya yang tidak diperbaharui. GSCM mengintegrasikan supply chain management dengan tujuan mengurangi dampak lingkungan yang diakibatkan siklus hidup produk (product life cycle) dengan melakukan harmonisasi dengan supply chain partner untuk melakukan tindakan-tindakan yang menunjang proses bisnis yang berwawasan lingkungan. Dalam mewujudkan hal ini, aktivitas-aktivitas yang terkait didalamnya adalah kerjasama suppliers dan customer, analisa proses dan operasi secara internal, pertimbangan faktorfaktor lingkungan dalam proses pengembangan produk dan pengawasan yang berkelanjutan antar siklus hidup produk (Corbett dan Klassen, 2006).

Rao (2002) mendeskripsikan tujuan GSCM sebagai konsep untuk membuat aliran material dalam proses bisnis memiliki nilai tambah dengan melakukan harmonisasi dan pengawasan terhadap aliran material, modal, informasi dan kerja. Kemudian tujuan berikutnya adalah menyediakan produk-produk yang berkualitas dan memberikan pelayanan yang tepat kepada konsumen dengan biaya dan resiko lingkungan yang minimal. Pengembangan dari kajian mengenai siklus hidup produk juga menunjukkan bahwa tindakan dari suatu perusahaan dalam tahap tertentu dari siklus hidup produk tidak secara efektif mengurangi dampak lingkungan pada keseluruhan siklus. Dalam hal ini kinerja dari keberlanjutan lingkungan dan ekologi tergantung pada kinerja supplier yang ada dalam siklus bisnis tersebut (Linton et al, 2007; Vachon dan Klassen, 2009; Simpson, Power dan Samson, 2007).

Terdapat tiga ruang lingkup GSCM yang penting dalam teori ekologi modern dan juga penting bagi manajemen lingkungan serta keberlangsungan secara umum. Pertama, penyertaan aspek-aspek lingkungan dalam rantai manajemen yang teritegrasi. Kedua, integrasi dari inovasi teknologi yang hasilnya bermanfaat bagi lingkungan melalui supply chain industri dan yang ketiga partisipasi dari aktor-aktor industri yang lebih luar bagi manajemen lingkungan dari produksi industri yang tujuan akhirnya adalah penguatan pembangunan- kapasitas Capacity-building) tata kelola lingkungan (Berger et al, 2001).

Untuk ikut serta dalam pertumbuhan yang berkelanjutan, GSCM harus diimplementasikan oleh semua sektor dan skala usaha termasuk didalamnya sektor Usaha Kecil Menengah (UKM). Dengan mengaplikasikan GSCM, UKM memiliki peran yang besar pada keberlanjutan perekonomian negara sekaligus juga berperan pada keseimbangan alam yang diakibatkan oleh proses produksi yang dilakukan.

Penelitian ini bertujuan untuk melakukan evaluasi terhadap penerapan GSCM yang dilakukan pada UKM Kuliner yang ada di Kota Palembang. Sebagai kota yang sebagian besar didominasi oleh bidang kuliner, sektor ini diunggulkan untuk dapat menopang 
pertumbuhan ekonomi dan meningkatkan pendapatan masyarakat yang ada di Kota Palembang. Kuliner yang cukup banyak dicari oleh pendatang saat ini terdapat 10 macam jenis makanan kuliner seperti, yaitu: Pempek, Tekwan, Laksan, Celimpungan, Martabak har, Kue masubah, Es kacang merah, Tempoyak, Srikayo, Lenggang (Dispindang 2012).

Dalam rangka ikut serta dalam pembangunan yang berkelanjutan, sektor UKM harus memiliki kemampuan untuk menghasilkan suatu produk yang berkualitas dan memiliki daya saing ungul dan memiliki inovasi sehingga dapat memberikan kepuasan terhadap konsumen, maka diperlukan suatu langkah dengan menghasilkan produk yang green (hijau) yang dimulai dari produksi sampai dengan produk tersebut sampai ketangan konsumen, seperti UKM kuliner kota Palembang sebaiknya dapat menerapkan suatu model GSCM.

\section{Literature Review}

Menurut Srivastava (2007), mendefinisikan Green supply chain management sebagai pengintegrasian pemikiran lingkungan ke dalam Supply Chain Management, termasuk desain produk, pembelian material dan seleksi pemasok, proses manufaktur, pengiriman produk akhir ke konsumen dan juga pengelolaan produk. Sebuah Rantai Pasok yang ramah lingkungan bertujuan membatasi limbah dalam sistem industri guna menghemat energi dan mencegah disipasi bahan berbahaya ke lingkungan

Pires, et.al. (2001) mengartikan Supply Chain Management (Manajemen Rantai Pasokan) sebagai sebuah jaringan supplier, manufaktur, perakitan, distribusi, dan fasilitas logistik yang membentuk fungsi pembelian dari material, transformasi material menjadi barang setengah jadi maupun produk jadi, dan proses distribusi dari produk-produk tersebut ke konsumen.

Supply Chain Management (SCM) atau manajemen rantai pasokan adalah kegiatan yang meliputi Koordinasi, penjadwalan dan pengendalian terhadap pengadaan, produksi, persediaan dan pengiriman produk ataupun layanan jasa kepada pelanggan yang mencakup administasi harian, operasi, logistik dan pengolahan informasi mulai dari pelanggan hingga ke pemasok. Green supply chain sangat penting untuk kesuksesan implementasi dari industrial ecosystem dan industrial ecology. Semua aktivitas di sepanjang supply chain memiliki resiko dan dampak negatif terhadap lingkungan. Menurut Beamon (1999), tujuan dari pengelolaan supply chain yang sadar lingkungan adalah mempertimbangkan dampak lingkungan akhir dan sekarang dari semua produk dan proses dalam rangka melindungi lingkungan alam.

Menurut Said (2006), prinsip dasar SCM seharusnya meliputi lima hal, yaitu: (1) Prinsip integrasi. Artinya semua elemen yang terlibat dalam rangkaian SCM berada dalam satu kesatuan yang kompak dan menyadari adanya saling ketergantungan; (2) Prinsip jejaring. Artinya semua elemen berada dalam hubungan kerja yang selaras; (3) Prinsip ujung ke ujung. Artinya proses operasinya mencakup elemen pemasok yang paling hulu sampai ke konsumen yang paling hilir; (4) Prinsip saling tergantung. Setiap elemen dalam SCM menyadari bahwa untuk mencapai manfaat bersaing diperlukan kerjasama yang saling menguntungkan; (5) Prinsip komunikasi. Artinya keakuratan data menjadi darah dalam jaringan untuk menjadi ketepatan informasi dan material. 
Dalam pelaksanaan Green Supply Chain Management terdapat beberapa fungsi operasional dan aktivitas-aktivitas penunjang diantaranya: (1) pengadaan hijau, (2) manufaktur hijau, (3) distribusi hijau. Pengadaan hijau (Green Procurement) Pengadaan hijau berkaitan dengan keadaan lingkungan pembelian yang terdiri dari keterlibatan dalam kegiatan pengurangan pembelian, pemakaian ulang dan daur ulang bahan pada proses pembelian. Pengadaan hijau adalah salah suatu solusi untuk lingkungan dan ekonomi konservatif bisnis dan konsep memperoleh pilihan produk dan jasa yang meminimalkan dampak lingkungan. Adapun kegiatan-kegiatan dalam pengadaan hijau antara lain (a) Pemilihan supplier Dalam sistem pengadaan hijau, pemasok tempat pembelian bahan hanya dari "mitra hijau" yang memiliki standar mutu lingkungan dan lulus proses audit serta mempertimbangkan pemasok yang mendapatkan ISO dan sertifikat terkait prestasi dalam konsep green; dan (b) Mempromosikan kegiatan daur ulang dalam usaha meningkatkan kesadaran lingkungan dan mengurangi penggunaan bahan yang berbahaya bagi lingkungan.

Manufaktur hijau (Green Manufacturing) Manufaktur hijau merupakan proses produksi yang menggunakan input dengan dampak lingkungan yang rendah, sangat efisien dan menghasilkan sedikit bahkan tidak adanya limbah atau polusi. Manfaat dari penerapan manufaktur hijau yaitu dapat menurunkan biaya bahan baku, keuntungan efisiensi produksi dan meningkatkan citra perusahaan. Kegiatan-kegiatan dalam manufaktur hijau antara lain: (a) Pengontrolan penggunaan zat berbahaya, pemeliharaan kualitas air dan kontrol kualitas input sebelum pengolahan; (b) Teknologi efisiensi energi yaitu dengan mengurangi daya konsumsi dalam produk, meningkatkan masa hidup produk untuk meningkatkan efisiensi dan produktivitas, meningkatkan kapasitas mesin, desain produk, dan lain-lain; (c) Mempromosikan penggunaan kembali/ daur ulang, meningkatkan kesadaran lingkungan dan mengurangi penggunaan bahan yang berbahaya bagi lingkungan.

Distribusi hijau (Green Distribution) Kegiatan dalam distribusi hijau yaitu kemasan hijau dan logistik hijau. Kemasan hijau, meliputi hemat kemasan, menggunakan bahan yang ramah lingkungan, bekerja sama dengan vendor untuk standarisasi kemasan, meminimalkan penggunaan bahan dan waktu untuk membongkar dan mempromosikan program daur ulang. Logistik hijau, meliputi pengiriman langsung ke pengguna situs, penggunaan kendaraan bahan bakar alternatif dan mendistribusikan produk dalam batch besar.

Logistik balik (Reverse Logistic) Logistik balik merupakan proses mengambil produk dari konsumen akhir untuk tujuan meningkatkan nilai dan pembuangan yang tepat. Kegiatan-kegiatan dalam logistik balik antara lain pengumpulan, gabungan inspeksi/ pemilihan/ penyortiran, pemulihan, redistribusi dan pembuangan.

Esensi Reverse Logistic merupakan usaha untuk mendapatkan nilai dari produk yang tidak dipakai lagi. Ketika suatu produk telah kehilangan nilainya, maka aktivitas Reverse Logistic dapat melakukan recovery terhadap produk tersebut untuk menjadi produk baru kembali dengan jalan mendaur ulang beberapa bagian atau komponen produk tersebut. Reverse logistics merupakan semua aktivitas yang didalamnya terdapat perencanaan, pemrosesan, mereduksi, membuang limbah berbahaya atau non berbahaya dari produksi, 
pengemasan dan penggunaan dari produk. Semua aktivitas tersebut termasuk proses dari distribusi reverse (Steven dalam Dyckhoff, 2004). Karena pergerakan aliran barang berlawanan dari aliran didalam rantai pasok konvensional reverse logistics sering juga disebut "logistic backward", Dimana aliran forward barang mengalir dari supplier ke pelaku manufaktur dan pengecer ke konsumen. Reverse logistics berurusan dengan semua aliran dari barang dan informasi yang penting untuk mengumpulkan penggunaan produk, pengemasan material, pembatalan produksi, dan yang lainnya. Lalu membawanya untuk diletakkan dimana barang itu dapat digunakan kembali, remanufaktur, mendaur ulang atau dihancurkan.

Aktivitas Reverse Logistic terdiri dari beberapa tahap antara lain: pengumpulan produk pada collection point, pemilahan, pemrosesan kembali, dan pembuangan bagian bagian yang tidak dapat digunakan kembali. Pengelolaan aktivitas Reverse Logistic pada setiap tahap perlu ditangani dengan baik, sehingga peluang ekonomi dan pemanfaatan lingkungan dari aktivitas Reverse Logistic dapat dicapai. Manajemen Logistic penting dalam rantai pasokan, tujuan dari sistem logistic sebagai fungsi logistic utama dan kebutuhan utama manajemen rantai pasokan terpadu (supply chain manajemen) (Kothler, 2006).

Terdapat tiga faktor pendorong yang dapat menimbulkan terjadinya reverse logistic (Yanwen, 2012) yaitu (1) Ekonomi-Retur produk dapat dijadikan sumber untuk pemulihan nilai dengen cara menggunakan kembali produk, remanufaktur merupakan suatu bagian yang akan digunakan sebagai cadangan atau sisa daur ulang untuk memulihkan nilai material; (2) Perundang-Undangan-Perundang-undangan yang dimaksud dimana ada suatu peraturan yang mengharuskan perusahaan untuk memperbaiki; (3) Good-Corporate Citizenship mementingkan suatu nilai atau prinsip dimana dorongan dari organisasi atau perusahaan yang terlibat bertanggung jawab dengan reverse logistic. Suatu perusahaan dapat disebut good corporate citizenship dilihat dari perilaku baik untuk orang disekitarnya.

\section{Metodologi Penelitian}

Rancangan penelitian yang digunakan dalam penelitian ini adalah kuantitatif deskriptif. Menurut Sugiyono (2012), penelitian deskriptif digunakan untuk mengumpulkan informasi mengenai suatu kondisi atau situasi dengan tujuan akhir untuk mendeskripsikan dan interpretasi. Dalam penelitian ini bukan saja melakukan tabulasi namun juga melakukan analisis yang sesuai, intrepretasi, perbandingan, identifikasi trend yang ada serta hubungan.

Populasi dalam penelitian ini adalah UKM kuliner khas Kota Palembang. Berdasarkan data dinas peridustrian, terdapat 356 UKM yang bergerak di bidang kuliner khas Kota Palembang. Penentuan sampel dilakukan dengan penentuan junlah sampel berdasarkan table penentuan jumlah sampel yang dikembangkan oleh Isaac dan Michael (Sugiyono, 2012). Dengan tabel ini, peneliti dapat secara langsung menentukan jumlah sampel berdasarkan jumlah populasi dan tingkat kesalahan yang dikehendaki. Berdasarkan rumus Slovin, dengan populasi jumlah UKM kuliner sebanyak 356 dan tingkat kesalahan yang ditetapkan adalah 5\%, maka dalam penelitian ini jumlah sampel yang akan diambil sebesar 10\% dari jumlah populasi yaitu sebanyak 36 UKM. Kemudian teknik sampling 


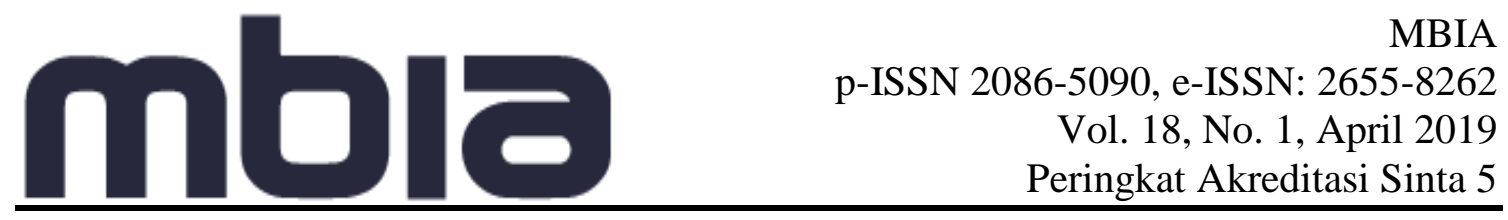

yang digunakan untuk memilih UKM yang akan dijadikan sampel adalah secara acak sederhana (simple random sampling).

Dalam menjawab permasalahan penelitian, digunakan data primer yang dikumpulkan dengan bantuan kuesioner yang terstruktur. Penggunaan data primer digunakan untuk tujuan untukmengetahui praktek-praktek GSCM pada UKM kuliner yang ada di Kota Palembang.

Kuesioner dibangun dengan menggunakan skala likert dari skala 1 sampai dengan 5, dan terdiri dari 3 bagian. Bagian pertama merupakan profil atau demografi dari UKM. Bagian kedua meliputi informasi praktek GSCM pada UKM. Bagian ketiga merupakan tantangan-tantangan dan hambatan yang dihadapi UKM dalam melaksanakan praktekpraktek GSCM. Data dianalisis dengan menggunakan metode statistik deskriptif kuantitatif. Dalam hal ini kuesioner akan diolah melalui analisis deskriptif dengan menghitung nilai mean dari setiap pertanyaan.

\section{Hasil dan Pembahasan}

Berdasarkan hasil pengumpulan data, dari 36 UKM kuliner di Kota Palembang, pemilik UKM tersebut 50 persen lebih merupakan perempuan sedangkan pemilik laki-laki hanya 45 persen. Hal ini memberi indikasi bahwa kepemilikan UKM kuliner didominasi oleh perempuan. Selanjutnya dari 36 pengisi kuesioner, 97 persen merupakan pemilik dan hanya 3 persen yang mengisi kuesioner adalah pengelola. Jenis kuliner yang menjadi target penelitian sebagian besar adalah pempek (47\%), Minuman (11\%), Pindang (25\%) dan kue khas Palembang (16\%). Untuk lama berdiri UKM tersebut, rata-rata UKM tersebut telah menjalankan usaha selama 5-9 tahun (47\%) dengan mayoritas memiliki latar belakang pendidikan adalah Sekolah Menengah Umum (SMU) sebanyak 47 persen lebih.

Tabel 1. Demografi UKM Kuliner Kota Palembang

\begin{tabular}{|cccc|}
\hline Jenis Kelamin & Jenis Kuliner & Lama Usaha & Latar Belakang Pendidikan \\
\hline Laki-laki (45\%) & Pempek (47,2\%) & $0-4$ thn $(11 \%)$ & SD (31\%) \\
\hline Perempuan (55\%) & Minuman (11,1\%) & $5-9$ thn $(47 \%)$ & SMP (6\%) \\
\hline & Pindang (25\%) & $10-14$ thn $(33 \%)$ & SMU (47\%) \\
\hline & Kue (16,7\%) & $>15$ thn $(8 \%)$ & Sarjana (17\%) \\
\hline
\end{tabular}

Sumber : Data diolah

Kesadaran akan pentingya GSCM merupakan indicator pertama yang ditanyakan kepada responden. Dari hasil kuesioner, diketahui bahwa mayoritas responden belum menyadari praktek-praktek rantai pasok yang berwawasan hijau. Dari hasil observasi di lapangan, rata-rata pemilik ataupun pengelola memahami konsep hijau namun tidak menyadari konsep GSCM pada proses produksi. 
Tabel 2. Kesadaran akan GSCM

\begin{tabular}{|clcc|}
\hline No & GSCM & f & \% \\
\hline $\mathbf{1}$ & Belum tahu & 26 & 72.22 \\
\hline $\mathbf{2}$ & Baru-baru ini (> 1 tahun) & 7 & 19.44 \\
\hline $\mathbf{3}$ & 1 tahun & 2 & 5.56 \\
\hline $\mathbf{4}$ & 2 tahun & 1 & 2.78 \\
\hline $\mathbf{5}$ & 3 tahun & 0 & 0 \\
\hline $\mathbf{6}$ & $<4$ tahun & 0 & 0 \\
\hline & Total & 36 & 100 \\
\hline
\end{tabular}

Sumber: data diolah

Reverse Logistic (RL) merupakan proses perencanaan, implementasi dan pengawasan terhadap bahan baku agar efisien dan efektif baik dalam proses persediaan, produk akhir serta informasi yang berkaitan dengan konsumsi sampai dengan menciptakan nilai yang sesuai pada pembuangan akhir.

Sangat penting bagi UKM untuk membangun jaringan RL dan pilihan alirannya dengan tujuan untuk mencegah adanya keetidakpuasan konsumen. Hal ini melibatkan terbentuknya aturan untuk mengawasi proses pengembalian baik dari sisi konsumen atau pemasok serta menciptakan matriks kerangka kerja untuk membangun hubungan dengan pemasok.

Berdasarkan hasil wawancara di lapangan, aplikasi RL pada UKM kuliner kota Palembang belum dilaksanakan sepenuhnya. Ini terlihat dari nilai rata-rata setiap indicator yang cenderung rendah. Walaupun pada praktek di lapangan pemilik menggunakan bahan baku yang memiliki kualitas baik, namun pemilik belum dapat memberika jaminan secara nyata penggunaan bahan baku kepada konsumen. Selain itu, pemilik ataupun pengelola UKM rata-rata belum memiliki sistem untuk mengawasi resiko lingkungan yang terjadi pada pihak pemasok. Kemudian pengelolaan lingkungan kemasan dan distribusi juga kurang diperhatikan oleh pemilik ataupun pengelola UKM. Kemasan-kemasan yang digunakan dalam hal ini masih memakai bahan-bahan yang berbahaya bagi kesehatan seperti sterofoam dan plasti-plastik yang berbahaya bagi lingkungan. 
Tabel 3. Reverse Logistik UKM Kuliner Kota Palembang

\begin{tabular}{|lr|}
\hline Jaminan Penggunaan bahan baku yang tepat pada pelanggan & Mean \\
\hline $\begin{array}{l}\text { Pemilik mengawasi resiko lingkungan yang dilakukan pada proses operasi } \\
\text { yang dilakukan pemasok }\end{array}$ & 1.4925 \\
\hline UKM mengelola aliran pengembalian dari material/bahan baku & 1.6371 \\
\hline UKM mengelola lingkungan kemasan dan distribusi & 2.5794 \\
\hline Sedapat mungkin bahan baku/material digunakan kembali (reuse) & 2.4806 \\
\hline Total & 9.3043 \\
\hline Rata-rata & 1.86086 \\
\hline
\end{tabular}

Sumber : Data diolah

Proses pengadaan hijau dapat didefinisikan sebagai suatu proses yang secara formal memperkenalkan dan mengintegrasikan permasalahan lingkungan pada proses pembelian yang dalam hal ini bahan baku atau barang yang dibeli untuk proses produksi memiliki pengaruh lingkungan yang minimal. Dengan kata lain bahan baku atau input yang dibeli untuk proses produksi adalah ramah lingkungan dan output yang dihasilkan juga ramah lingkungan.

Secara spesifik, untuk meminimalkan dampak lingkungan pada proses rantai pasok yang berkaitan dengan point pengadaan, pendekatan yang dilakukan meliputi pembelian bahan atau input yang memiliki label eko (eco-labelled), pengadopsian kriteria lingkungan pada pemasok yang terlibat dalam proses produksi, serta kolaborasi untuk mengaplikasikan proses pengawaan yang berwawasan hijau dengan para pemaok yang telibat (Collichia et al, 2011)

Untuk proses pengadaan atau procurement, berdasarkan hasil pengolahan data mengsindikasikan bahwa UKM kuliner di Kota Palembang belum mengaplikasikan proses yang berwawasan hijau. Dalam hal ini setiap indikator pada proses pengadaan yang berwawasan hijau nilainya masih rendah. 
Tabel 4. Pengadaan Hijau (Green Procurement) Pada UKM

\begin{tabular}{|lc|}
\hline Pengadaan Hijau (Green Procurement) & Mean \\
\hline Adopsi kriteria lingkungan dalam menilai sistem pemasok & 2.0588 \\
\hline Kolaborasi lingkungan dengan pemasok & 2.1765 \\
\hline Pembelian bahan yang berlabel Eco (Eco-labelled product) & 1.369 \\
\hline Persyaratan sertifikasi lingkungan bagi pemasok & 1.0574 \\
\hline Total & \\
\hline Rata-rata & 6.6617 \\
\hline
\end{tabular}

Sumber: Data diolah

\section{Simpulan}

Dari hasil kuesioner, diketahui bahwa mayoritas responden belum menyadari praktekpraktek rantai pasok yang berwawasan hijau. Dari hasil observasi di lapangan, rata-rata pemilik ataupun pengelola memahami konsep hijau namun tidak menyadari konsep GSCM pada proses produksi, dalam hal Praktek GSCM UKM Kuliner Kota Palembang Mengenai Reverse Logistic, Berdasarkan hasil wawancara di lapangan, aplikasi RL pada UKM kuliner kota Palembang belum dilaksanakan sepenuhnya. Ini terlihat dari nilai ratarata setiap indicator yang cenderung rendah. Walaupun pada praktek di lapangan pemilik menggunakan bahan baku yang memiliki kualitas baik, namun pemilik belum dapat memberikan jaminan secara nyata penggunaan bahan baku kepada konsumen. . Selain itu, pemilik ataupun pengelola UKM rata-rata belum memiliki sistem untuk mengawasi resiko lingkungan yang terjadi pada pihak pemasok. Sedangkan pengelolaan lingkungan, kemasan dan distribusi juga kurang diperhatikan oleh pemilik ataupun pengelola UKM. Kemasan-kemasan yang digunakan dalam hal ini masih memakai bahan-bahan yang berbahaya bagi kesehatan seperti sterofoam dan plasti-plastik yang berbahaya bagi lingkungan, diketahui dari 5 aspek reverse logistic yang dianalisis mengsindikasikan bahwa UKM kuliner di Kota Palembang belum mengaplikasikan proses yang berwawasan hijau. Dalam hal ini setiap indikator pada proses pengadaan yang berwawasan hijau nilainya masih rendah. Sedangkan Praktek Pengadaan Hijau (Green Procurement) Pada UKM dari hasil analisis terhadap 4 aspek : Adopsi kriteria lingkungan dalam menilai sistem pemasok, Kolaborasi lingkungan dengan pemasok, Pembelian 


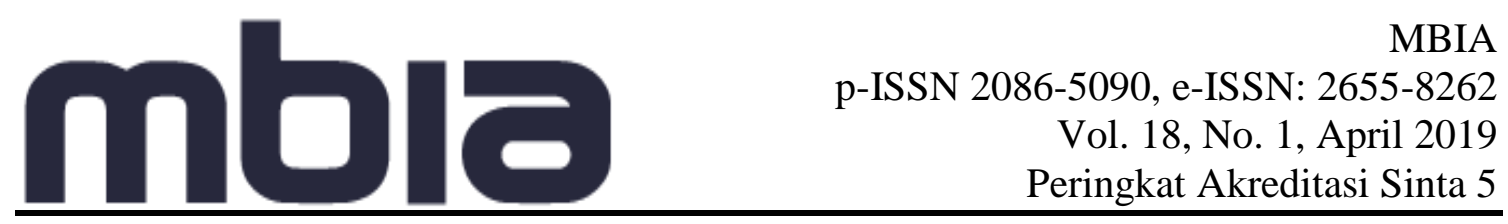

bahan yang berlabel Eco (Eco-labelled product), Persyaratan sertifikasi lingkungan bagi pemasok, Sejalan dengan hasil dari variable-variabel GSCM sebelumnya hasil penelitian serta analisis terhadap 2 aspek GSCM pada UKM kuliner khas kota Palembang, maka diperlukan suatu dukungan pemerintah, baik pemerintah daerah maupun pemerintah pusat agar para UKM dapat menerapakan Konsep GSCM pada sektor UKM kuliner, dimana sektor ini adalah salah satu sektor yang dapat meningkatkan ekonomi masyarakat dan secara otomatis akan meningkatkan ekonomi daerah melalui pendapatan Asli Daerah (PAD).

\section{Daftar Pustaka}

Beamon, Benita M. (1999). Measuring Supply Chain Performance. International Journal of Operations \& Production Management, 19(3), pp. 275- 292.

Berger, G., Flynn, A., Hines, F., \& Johns, R. (2001). Ecological modernization as a basis for environmental policy: Current environmental discourse and policy and the implications on environmental supply chain management. Innovation: The European Journal of Social Science Research, 14(1), pp. 55-72.

Colicchia, C., Melacini, M., \& Perotti, S. (2011). Benchmarking supply chain sustainability: Insights from a field study. Benchmarking: An International Journal, 18(5), hal 705-732.

Corbett, C.J., \& Klassen, R.D. (2006). Extending the horizons : Environmental excellence as key to improving operations. Manufacturing \& Service Operations Management, 8(1), pp. 5-22.

Krause, D. R., Vachon, S., \& Klassen, R. D. (2009). Special topic forum on sustainable supply chain management: Introduction and reflections on the role of purchasing management. Journal of Supply Chain Management, 45(4), pp.18-25.

Kotler, P. (2006). Manajemen pemasaran, jilid I, Edisi kesebelas. Jakarta: P.T Indeks Gramedia.

Linton, J. D., Klassen, R., \& Jayaraman, V. (2007). Sustainable supply chains: An introduction. Journal of operations management, 25(6), pp. 1075-1082.

Pires, et al. (2001). Measuring Supply Chain Performance. Orlando.

Rao P. (2002). Greening the supply chain: A new initiative in South East Asia. International Journal of Operations and Production Management, 22, pp. 632-655.

Said, A.I, et al. (2006). Produktivitas dan Efisiensi dengan Supply Chain Management. Jakarta: Penerbit PPM.

Simpson, D., Power, D., \& Samson, D. (2007). Greening the automotive supply chain: a relationship perspective. International Journal of Operations \& Production Management, 27(1), pp. 28-48.

Srivastava, S.K. (2007). Green Supply-Chain Management: A State-of-the-Art Literature Review. International Journal of Management Reviews, 9(1), pp. 53-80.

Steven, M. (2004). Networks in reverse logistics. In H. Dyckhoff, R. Lackes, \& J. Reese (Eds.), Supply chain management and reverse logistics (pp. 163-180). Berlin: Springer.

Sugiyono. (2012). Metode Penelitian Kuantitatif Kualitatif dan R\&D. Bandung: Alfabeta.

$\mathrm{Wu}$, Y. (2012). Advanced Technology in Teaching-Proceedings of the $20093 \mathrm{rd}$ International Conference on Teaching and Computational Science (WTCS 2009). Heidelberg: Springer 


\section{Copyright Disclaimer}

Copyright for this article is retained by the author(s), with first publication rights granted to the journal. 